\title{
EXTENSION OFFICERS AS SOCIAL COORDINATORS: COMPARISONS BETWEEN AGRICULTURAL AND FISHING COMMUNITIES IN JAPAN
}

\author{
Kosuke TAKEMURA ${ }^{1)}$, Yukiko UCHIDA ${ }^{2)}$, and Masahiro FUJINO ${ }^{3)}$ \\ ${ }^{1)}$ Faculty of Economics, Shiga University, Japan \\ ${ }^{2}$ Kokoro Research Center, Kyoto University, Japan \\ ${ }^{3)}$ Graduate School of Education, Kyoto University, Japan
}

\begin{abstract}
Literature suggests that social capital, which often promotes human welfare, requires sensitive handling to build and maintain. The current study investigated the role of extension officers (fukyu-shidoin) in Japanese agricultural and fishing communities, who help farmers/fishers in both technical and social matters. Past research found that in Japanese agricultural communities, extension officers' activities, social skills, and relationships with their colleagues had effects on social capital and problem solving in communities. We conducted a nation-wide survey of fishery extension officers and found that the findings in agricultural communities were largely replicated in fishing communities with only one difference: Officers' acitivities to provide a future vision had a positive effect for problem solving in agricultural communities. For fisheries, however, such activities were more effective when the officer had worked for the community for a longer period of time. This could be explained by the higher level of uncertainty in fishing than farming.
\end{abstract}

Key words: social capital, agriculture, fishery, extension officers

\section{INTRODUCTION}

The current research addresses how to build and maintain social capital in local communities. Social capital, such as trust relationships, can promote the welfare of community residents as it promotes cooperative social relationships (Pretty, 2003). However, social relationships are vulnerable and not necessarily easy to build, and thus require sensitive handling. Additionally, social capital is intangible. In human societies, sometimes there are individuals who work for such capital with professional skills and knowledge. One example is extension officers (普及指導員; fukyu-shidoin) of agriculture, who come into an agricultural community from the outside as a third party (local government), and work to help farmers not only in technical matters but also in social

This research was supported by grants from the Tokyo Fisheries Promotion Foundation.

The authors would like to thank the Japan Fisheries Development and Extension Personnel Association, the Tokyo Fisheries Promotion Foundation, the Fisheries Agency of Japan, and the Japan Agricultural Development and Extension Personnel Association, for their help with data collection. The authors also thank Pamela Taylor and the reviewers for their helpful comments on earlier versions of this manuscript.

Correspondence concerning this article should be Kosuke Takemura, Faculty of Economics, Shiga University, 1-1-1 Banba, Hikone, Shiga 522-8522, Japan (e-mail: boz.takemura@gmail.com). 
issues. They help facilitate organization among farmers as well as bridge farmers with relevant parties (e.g., the local government). A previous study found that their social skills promoted trust relationships among community residents (Takemura, Uchida, \& Yoshikawa, 2014). The current study aims to examine if these functions of extension officers in agricultural communities are also found in fishing communities, which have different patterns of socio-cultural environment and social practice.

\section{Social capital and community welfare}

Social capital can be broadly defined as the benefits of investing in social relationships (Wilson, O’Brien, \& Sesma, 2009), similar to financial capital and human capital (investing in individual capacities, such as education). It has been suggested that social capital increases community welfare, such as regional incomes, life satisfaction, and life expectancy (see Pretty, 2003; Putnam, 2000; Wilkinson, 1999, for reviews; see also Svendsen \& Svendsen, 2004, for potential negative effects of social capital on welfare). One explanation of the positive effect of social capital is that it can save transaction costs (Pretty, 2003). When two individuals trust each other, they could invest in collective activities with less anxiety, knowing that the other will do so as well. Otherwise, they need to invest additional costs (i.e., money and time) to monitor the potential opponent. Trust relationships help individuals save such costs and invest money and time in other things such as health (see House, Landis, \& Umberson, 1988; Uchino, Cacioppo, \& KiecoltGlaser, 1996, for relationships between health and social capital).

\section{Roles of social coordinators}

Though social capital plays critical roles in the community, it generally takes time to build social capital (e.g., Sampson, Raudenbush, \& Earls, 1997). Additionally, once trust relationships have been established, they can easily break down (e.g., Mulder, van Dijk, De Cremer, \& Wilke, 2006). Social capital thus requires efforts to build and maintain it.

Some individuals serve in the role of social coordinators, and facilitate building and maintaining social capital. For example, Harada, Konishi, Teraoka, and Ura (2011) found that public health nurses in Japan, professionals that support community residents' health, played the role of intermediary in social relationships. They suggested that public health nurses helped to strengthen relationships within local communities (i.e., bonding social capital; Putnam, 2000), and contributed to establishing relationships between community residents and other types of professionals, such as nursery school teachers (i.e., bridging social capital; Putnam, 2000). Another example is facilitators in dialogue between scientists and lay people in science café (also known as cafes scientifiques). Hidaka, Mizuki, and Sato (2014) found that lay people engaged in a conversation more actively when a facilitator was present than when not. This suggests that facilitators can make interactions smoother and promote bi-directional communication between scientists and lay people, which sometimes plays essential roles in innovation (e.g., Wood et al., 2014, for a case of agriculture). 


\section{Extension officers of agriculture}

A previous study (Takemura et al., 2014) has investigated one such professional coordinator's role in Japan: the role of extension officers of agriculture. The Japanese extension system for agriculture, which started in 1948, was meant to help farmers acquire useful, appropriate, and practical knowledge in the domain of agriculture. As of 2010, there were approximately 7,000 officers in Japan, each of them belonging to a prefectural government. The job of extension officers is to help farmers in person to acquire technical and managerial knowledge and other skills in the domain of agriculture (Ministry of Agriculture, Forestry and Fisheries, Japan, n.d.). In addition, they are expected to serve "coordinator" function (Ministry of Agriculture, Forestry and Fisheries, Japan, 2010, 2012). Coordinator function means to "help local farmers and related parties share future goals, clarify tasks they need to address, develop an approach to the tasks, and conduct it, under the cooperation with leading farmers as well as relevant organizations within and around local communities." Thus, extension officers are supposed to help farmers not only with skills and knowledge directly related to agriculture, but also help farmers build and maintain social capital (see also Zakaria \& Nagata, 2010).

In fact, Takemura et al. (2014) has shown the importance of social capital in agricultural communities and effects of extension officers' skills on social capital. A large nation-wide survey of extension officers was conducted, and the results showed that 1) trust relationships (one component of social capital) among community residents increased their life quality; 2) the level of trust relationships was positively associated with extension officers' communication skills and harmonious relationships among their colleagues; and 3) social capital-related activities (e.g., assistance for building organizations among farmers) were particularly effective for solving problems farmers faced.

It is yet unclear if these findings are generalized to other types of communities engaging in different economic activities, such as fishery. A recent study shows that social capital is essential in fishing communities as well (Gutiérrez, Hilborn, \& Defeo, 2011). On the other hand, cross-cultural studies of psychology have found that farmers are more sensitive to social relationships within community than people engaging in other types of economic activities (e.g., Berry, 1967), implying that social capital may be more important in agricultural communities than fishing communities. Thus, the generalizability of the findings from agriculture to fishery is not obvious and awaits empirical investigations.

\section{Extension officers of fishery}

The Japanese extension system for fishery started in 1953 (Japan Fisheries Development and Extension Personnel Association, 2009). As of 2012, there were approximately 460 extension officers of fishery in Japan ${ }^{1}$, each of them belonging to a prefectural government just as extension officers of agriculture. The job of extension officers of fishery is "to disseminate fishery technologies, fostering of fishers, as well as acting as intermediary between fishers and government," and they are expected to foster

\footnotetext{
${ }^{1}$ Officers in two prefectures which do not belong to the Japan Fisheries Development and Extension Personnel Association were not included in this number.
} 
fishers who actively work in fishery management by interacting with them in person (Japan Fisheries Development and Extension Personnel Association, 2009, pp. 11-12). This definition assumes that the extension officers of fishery also have coordinator functions.

In the current study, we conducted a nation-wide survey of fisheries extension officers in Japan. The procedures and measures were identical with those of the previous study on agricultural extension officers (Takemura et al., 2014). By analyzing a combined dataset from the agriculture and fishery surveys, we examined if the following findings from the agricultural communities were replicated in fishing communities:

1) Perceived life quality of community residents are positively correlated with perceived trust relationships among them.

2) Perceived trust relationships among community residents are positively correlated with officer's behavioral tendency and skills (i.e., behavioral tendency toward collaborations, extraversion, communication skills, knowledge and technical skills of agriculture) as well as social relationships the officer has (relationships with community, relationships at their workplace).

3) Extension activities relating to social capital are effective in solving problems that farmers face.

We expected that the above findings from agricultural communities would be generally replicated in fishing communities as fishers also need to cooperate and collaborate with each other in order to make their economic activities sustainable (Gutiérrez et al., 2011). Thus, we expected that extension activities promoting the communities' social capital would help solve several problems, not only in the agricultural communities, but also in fishing communities.

However, as for activities to provide a vision for the future, which is one of the social capital-related activities (Takemura et al., 2014), we expected that they might have different effects between agriculture and fishery. Extension officers are supposed to help community members share future goals (Ministry of Agriculture, Forestry and Fisheries, Japan, 2010, 2012), and it has been reported that officers sometimes present a future vision for farmers (Takemura et al., 2014). The effects of such activities may be weak or conditional in fishery because it is generally difficult to predict the future in fishery due to the high level of environmental variability (e.g., Roughgarden \& Smith, 1996).

\section{METHOD}

\section{Respondents}

Table 1 provides summary of respondent characteristics. For agriculture, we used data that was reported in the previous study (Data 1 of Takemura et al., 2014). The data was collected with the cooperation of the Japan Agricultural Development and Extension Personnel Association. We called all the agricultural extension officers in Japan $(N=7,241)$ for the study, and 4,355 extension officers participated in the study (response ratio was $60.0 \%$ ). Respondents from all but two prefectures completed the online survey (for Saitama and Wakayama prefectures, the surveys were sent and returned through the mail because computers at their workplaces could not access the survey website due to access limitations).

For fishery, we collected data by the same method as the data for agriculture. With the cooperation of the Japan Fisheries Development and Extension Personnel Association, we called all the fisheries extension 
Table 1. Summary of respondent characteristics

\begin{tabular}{|c|c|c|c|}
\hline & & Agriculture & Fishery \\
\hline Study period & & $\begin{array}{l}\text { September-October, } \\
2010\end{array}$ & $\begin{array}{l}\text { August-September, } \\
2012\end{array}$ \\
\hline Population & & $\begin{array}{l}\text { Agricultural extension } \\
\text { officer in Japan }\end{array}$ & $\begin{array}{l}\text { Fisheries extension } \\
\text { officer in Japan }\end{array}$ \\
\hline Sample size & & 4,355 & 276 \\
\hline Response rate & & $60 \%$ & $60 \%$ \\
\hline \multirow[t]{3}{*}{ Gender } & Female & $23 \%$ & $5 \%$ \\
\hline & Male & $60 \%$ & $72 \%$ \\
\hline & No response & $17 \%$ & $23 \%$ \\
\hline \multirow[t]{6}{*}{ Age } & $20 \mathrm{~s}$ & $6 \%$ & $5 \%$ \\
\hline & $30 \mathrm{~s}$ & $18 \%$ & $22 \%$ \\
\hline & $40 \mathrm{~s}$ & $37 \%$ & $31 \%$ \\
\hline & $50 \mathrm{~s}$ & $24 \%$ & $24 \%$ \\
\hline & $60 \mathrm{~s}$ & $1 \%$ & $2 \%$ \\
\hline & No response & $13 \%$ & $17 \%$ \\
\hline \multirow{5}{*}{$\begin{array}{l}\text { Number of years of } \\
\text { experience working as } \\
\text { an extension officer }\end{array}$} & 3 or less & $11 \%$ & $18 \%$ \\
\hline & Between 4-10 & $16 \%$ & $26 \%$ \\
\hline & Between 10-15 & $15 \%$ & $4 \%$ \\
\hline & 15 or longer & $38 \%$ & $39 \%$ \\
\hline & No response & $20 \%$ & $12 \%$ \\
\hline \multirow[t]{2}{*}{$\begin{array}{l}\text { Perceived state of } \\
\text { the community }(M \pm S D)\end{array}$} & $\begin{array}{l}\text { Trust relationships } \\
\text { among residents }\end{array}$ & $5.27 \pm 0.75$ & $4.97 \pm 0.79$ \\
\hline & Life quality of residents & $3.83 \pm 1.26$ & $3.62 \pm 1.44$ \\
\hline \multirow{6}{*}{$\begin{array}{l}\text { Officer's skills and social } \\
\text { relationships }(\mathrm{M} \pm \mathrm{SD})\end{array}$} & Collaboration index & $2.63 \pm 0.34$ & $2.62 \pm 0.36$ \\
\hline & Extraversion & $3.87 \pm 1.08$ & $3.95 \pm 1.03$ \\
\hline & Communication skills & $0.28 \pm 1.41$ & $0.14 \pm 1.46$ \\
\hline & $\begin{array}{l}\text { Knowledge and } \\
\text { technical skills }\end{array}$ & $-0.50 \pm 1.58$ & $-0.45 \pm 1.52$ \\
\hline & Tie with community & $0.63 \pm 1.15$ & $0.65 \pm 1.18$ \\
\hline & $\begin{array}{l}\text { Interpersonal } \\
\text { relationships at } \\
\text { the workplace }\end{array}$ & $1.03 \pm 1.29$ & $1.25 \pm 1.31$ \\
\hline
\end{tabular}


officers working in prefectures that belonged to the Association $(N=460)$, and 276 extension officers participated in the study (response ratio was $60.0 \%$ ). Respondents completed the online survey.

\section{Measures}

Perceived state of the community. The respondents were asked about the state of the community where the respondents were working at that time. The respondents were instructed to indicate life quality of the community residents ( 2 items, "The community residents are satisfied with their circumstances of life," "The living conditions of the community residents were all right"; $\alpha \mathrm{s}=.78$ and .84 for agriculture and fishery, respectively). The respondents were also asked about trust relationships among community residents ( 7 items, e.g., "I think the community residents trust each other," "The interpersonal relationships among the community residents are generally smooth"; $\alpha=.82$ and .79 for agriculture and fishery, respectively). Response options were provided on 7 -point scales $(1=$ Strongly disagree to $7=$ Strongly agree $)$.

The respondent's skills and social relationships. We administered a modified version of Tsutsui's (2005) collaboration activity scale, which was designed to measure a behavioral tendency for collaborations and communications with other related parties such as agricultural/fisheries cooperatives and local government. Sample items included "I hear about services and actual situations of other related organizations (including resident organizations) from themselves," "I know what kind of professionals are in other related organizations (including resident organizations)," "I ask for cooperation of other related organizations (including resident organizations)," ( $\alpha=.84$ and .85 for agriculture and fishery, respectively). Response options were provided on 4-point scales $(1=$ Not at all to $4=$ Very much $)$. We call this the collaboration index hereafter.

We also asked about their self-evaluation of communication skills ("What do you feel about your own current communication skills as an extension officer?") and self-evaluation of their knowledge and technical skills ("What do you feel about the current level of your knowledge and techniques which are directly related to extension activities?"), which related to the major functions of extension officers ("coordinator" function and "specialist" function, respectively). For both items, response options were provided on 7-point scales $(-3=$ Far from enough to $3=$ Good enough). They also worked on a 10 -item scale of extraversion developed by Goldberg (1992). Sample items were "I am the life of the party" and "I start conversations" ( 1 = Strongly disagree to $7=$ Strongly agree; $\alpha=.91$ and .88 for agriculture and fishery, respectively). Extraversion was measured as one personality trait that might promote their coordinator function.

Two questions were administered to assess social relationships the respondents had. The first one was about their relationships with the community they were working for (hereafter referred to as "tie with community"), ranged from -3 (I am independent and separate from the community) to 3 (I am connected with the community). The second one was about relationship harmony at their workplace (i.e., extension center) $(-3=$ Very bad to $3=$ Very good $)$.

Extension activities they had conducted. The respondents were asked to recall one of their recent experiences in which they were faced with a difficulty in one of the cases in their charge ${ }^{2}$. Then they were instructed to indicate all the extension activities they had conducted in that situation from the list of activities. The list included six social capital-related activities (Takemura et al., 2014): 1) Providing a vision for the future; 2) Assistance for building organizations and collaboration among farmers/fishers; 3) Identifying specific problems the community has; 4) Assistance for the development of agricultural/fishing communities; 5) Collaboration and coordination with relevant organizations; and 6) Assistance to foster the sustainable workforce. Past research on agricultural communities (Takemura et al., 2014) found that among several different extension activities, these activities had high loadings on the same factor. All of them relate to the social capital of communities. They are activities promoting collaboration among community members as well as related parties (activities 2 and 5), activities targeting a community as a whole rather than individual farmers/fishers (activities 3 and 4), and support to deal with issues that are effectively solved when community members collaborate (activities 1 and 6; Morimoto, 2009; Morita, Yagi, \& Abe, 2009). The current study examined whether the effects of these activities were different in agriculture and fishery.

After indicating all the conducted activities, they completed the following four items, all of which were considered to reflect their assessment of their activities; the first two items asked how satisfied they were, and

\footnotetext{
${ }^{2}$ The communities that they recalled for this question might be different from the communities that they were working for at that time.
} 
how satisfied they thought the community residents were with their activities as a whole in that situation. For both items, they indicated the level of satisfaction using the same scale ranging from 0 to 100 . The other two questions were about positive feedback from the community residents. The first item asked how often the community residents showed their gratitude to the respondents (from $0=$ Never to 3 =Very often). The second asked how pleased the community residents were about the respondent's activities in total (from $-3=$ Not pleased at all to $3=$ Fairly pleased). To give equal weights to the four items, we rescaled the items so that each ranged from 0 to 1 . The average of the rescaled items forms our measure of performance $(\alpha=.87$ and .65 for agriculture and fishery, respectively).

The respondents also indicated if the community engaged in aquafarming, and how long they had been working for the community (hereafter referred to as "service years"). These variables were included in analyses as potential moderators of the effects of social capital-related extension activities. In addition, they completed demographic items, including gender, age and number of years of experience working as an extension officer.

\section{RESULTS}

\section{Trust relationships and life quality of community residents}

We examined if the association between perceived trust relationships among community residents and perceived life quality of community residents was the same between agriculture and fishery (see Table 1 for means and standard deviations of these variables). Multiple regression analysis of life quality on trust relationships (centered around the overall mean), dummy-coded variable for industry (agriculture was the reference category), and their interaction was performed. Table 2 shows the result of the regression analysis. The coefficient of trust relationships was positive, indicating that life quality of residents tended to be high in communities where residents trusted each other. Industry had neither a significant main effect nor interaction effect with trust relationships on life quality. Together, the regression analysis revealed that perceived trust relationships were positively associated with perceived life quality for both agriculture and fishery.

\section{Correlates of trust relationships of communities}

Takemura et al. (2014) found that trust relationships among community residents was positively correlated with officer's skills and personalities (i.e., collaboration index, extraversion, communication skills, and knowledge and technical skills) and his or her social relationships (i.e., tie with community, and interpersonal relationships at the workplace). We examined if these associations were the same between agriculture and

Table 2. Association between perceived trust relationships and perceived life quality of community residents

\begin{tabular}{lcccc}
\hline & $b$ & $(S E)$ & $t$ & $p$ \\
\hline Trust relationships (centered) & .23 & $(.03)$ & 7.92 & $<.001$ \\
Industry (ref = agriculture) & .29 & $(.58)$ & .49 & .623 \\
Trust relationships $\times$ Industry & -.09 & $(.12)$ & -.74 & .458 \\
\hline Adjusted $R^{2}$ & .02 & & & $<.001$ \\
\hline
\end{tabular}


fishery (see Table 1 for means and standard deviations of these variables). A series of regression analyses was performed of trust relationships on each of these variables, dummy-coded industry (agriculture was the reference category) and their interaction effect. It was revealed that trust relationships among community residents was positively associated with officer's collaboration index, $b=.37, p<.001$, extraversion, $b=.09$, $p<.001$, communication skills, $b=.09, p<.001$, knowledge and technical skills, $b=.04$, $p<.001$, tie with community, $b=.23, p<.001$, and interpersonal relationships at the workplace, $b=.14, p<.001$. None of these associations was not qualified by industry, $|b| \mathrm{s}<.02, p \mathrm{~s}>.762$.

\section{Effects of social capital-related extension activities to solve problems in communities}

We examined how effective each type of extension activity was to solve problems that farmers/fishers faced (see Table 3 for the frequencies of the activities). Fig. 1 shows the performance scores when the respective activity was conducted and when it was not, as a function of industry (agriculture vs. fishery). For each activity, the performance score was analyzed by 2 (agriculture vs. fishery) $\times 2$ (conducted vs. not conducted) ANOVA (i.e., six separate ANOVAs were conducted). First, the main effect of industry (agriculture vs. fishery) did not reach the level of statistical significance in all the analyses, $F \mathrm{~s}(1$, $4139)<2.57, p s>.109, \eta_{\mathrm{p}}{ }^{2} \mathrm{~s}<.001$, except for the ANOVA examining the effect of "assistance for the development of agricultural/fishing communities," $F(1,4139)=8.32$, $p=.004, \eta_{\mathrm{p}}{ }^{2}=.002$, indicating that the performance score was higher for agriculture than for fishery in this analysis. Second, for all the activities, the performance score was higher when the respective activity was conducted than when it was not conducted, $F \mathrm{~s}(1$, $4139)>36.70, p \mathrm{~s}<.001, \eta_{\mathrm{p}}{ }^{2} \mathrm{~s}>.008$. This suggests that social capital-related extension activities were effective in solving problems in the communities. Third, the effects of activities were not qualified by industry, $F \mathrm{~s}(1,4139)<3.26, p \mathrm{~s}>.070, \eta_{\mathrm{p}}{ }^{2} \mathrm{~s}<.001$,

Table 3. Extension activities conducted in difficult situations respondents experienced

\begin{tabular}{|c|c|c|c|c|}
\hline & \multicolumn{2}{|c|}{ Agriculture } & \multicolumn{2}{|c|}{ Fishery } \\
\hline & $N$ & $\%$ & $N$ & $\%$ \\
\hline Providing a vision for the future & 1573 & $36 \%$ & 60 & $22 \%$ \\
\hline $\begin{array}{l}\text { Assistance for building organizations and collaboration } \\
\text { among farmers/fishers }\end{array}$ & 1912 & $44 \%$ & 73 & $26 \%$ \\
\hline Identifying specific problems the community has & 1668 & $38 \%$ & 76 & $28 \%$ \\
\hline $\begin{array}{l}\text { Assistance for the development of agricultural/fishing } \\
\text { communities }\end{array}$ & 1358 & $31 \%$ & 98 & $36 \%$ \\
\hline Collaboration and coordination with relevant organizations & 2757 & $63 \%$ & 146 & $53 \%$ \\
\hline Assistance to foster the sustainable workforce & 2175 & $50 \%$ & 100 & $36 \%$ \\
\hline
\end{tabular}




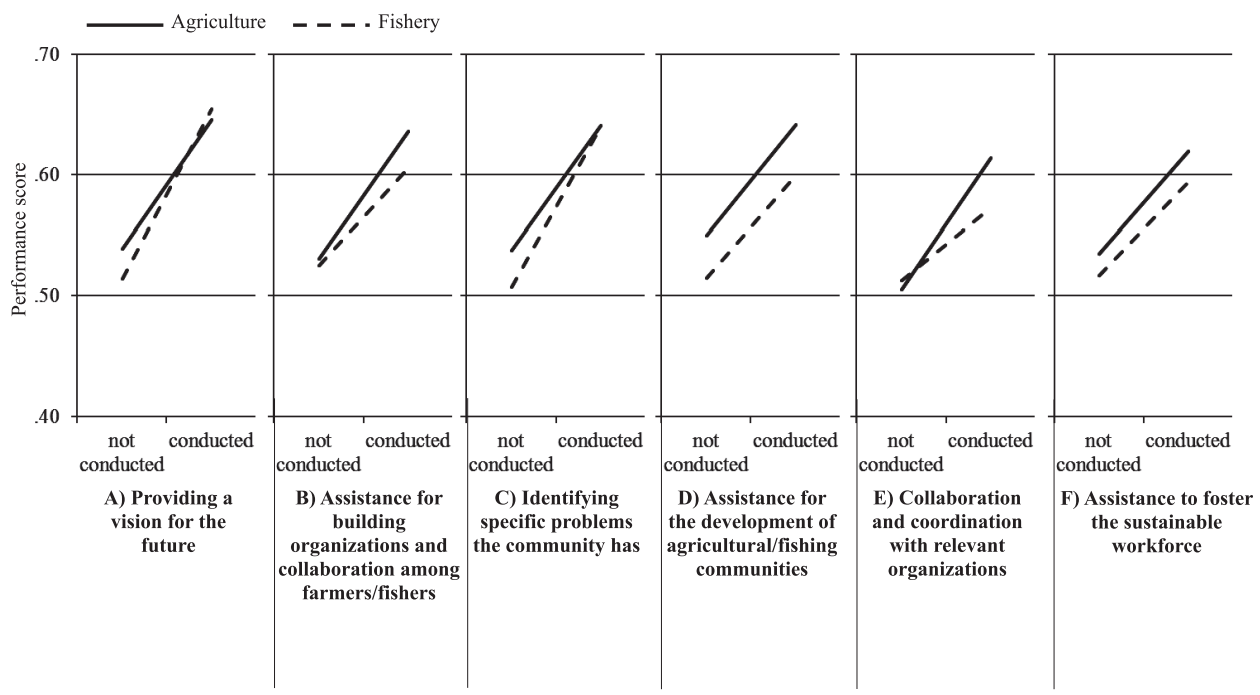

Fig. 1. Performance scores of extension activities as a function of type of activity and industry.

suggesting that social capital-related activities were effective not only in agricultural but also in fishing communities.

\section{Moderator analyses}

We investigated factors that moderated the effects of social capital-related extension activities. First, we examined if the effects of the social capital-related activities varied between aquafarming fishing communities and non-aquafarming fishing communities. Among the fisheries extension officers, more than half of them $(N=149 ; 54 \%)$ indicated the communities they worked for engaged in aquafarming, while only $35 \%(N=97)$ of officers reported the communities did not (30 officers did not answer the respective question). Aquafarming is somewhat similar to agriculture in terms of efforts to control natural environments. Therefore, the similarities found between agricultural and fishing communities in the effects of social capital-related activities might be due to communities engaging in aquafarming. To examine if that was the case, we compared aquafarming fishing communities and non-aquafarming fishing communities. For each activity, the performance score was analyzed by 2 (aquafarming vs. no aquafarming) $\times 2$ (conducted vs. not conducted) ANOVA (i.e., six separate ANOVAs were conducted). The main effects of aquafarming were not significant for all the analyses, $F \mathrm{~s}(1,234)<2.09, p \mathrm{~s}>.140$, $\eta_{\mathrm{p}}{ }^{2} \mathrm{~s}<.009$. The effect of activity was significant for all the types of activities, indicating that the performance score was higher when the respective activity was conducted than when it was not, $F \mathrm{~s}(1,234)>5.51, p \mathrm{~s}<.020, \eta_{\mathrm{p}}{ }^{2} \mathrm{~s}>.020$. The interaction effects were not significant for all the analyses, $F_{\mathrm{s}}(1,234)<2.08, p \mathrm{~s}>.150, \eta_{\mathrm{p}}{ }^{2} \mathrm{~s}<.009$. Thus, the effects of social capital-related extension activities were not dependent on aquafarming.

Second, we also examined the moderating role of service years, or length of time period officers had worked for the community $(M=2.91, M d=2, S D=2.83)$ for 


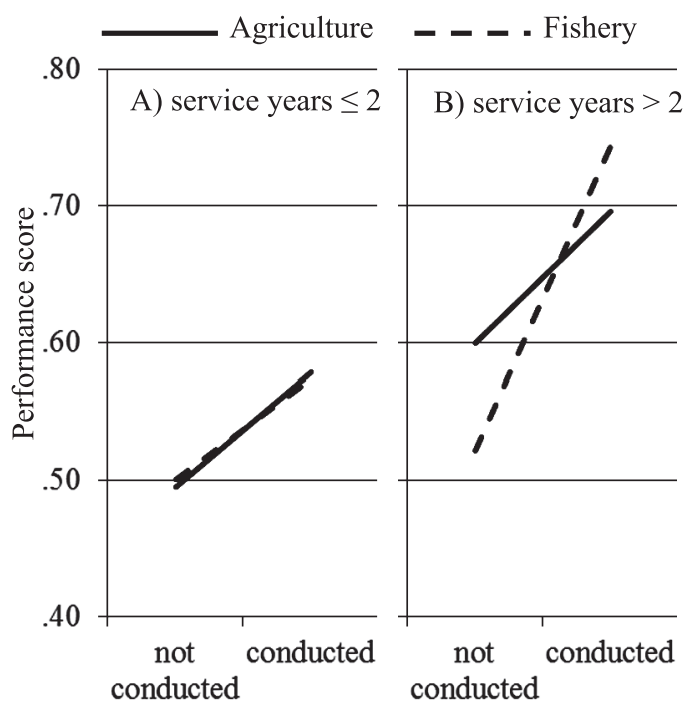

Providing a vision for the future

Fig. 2. Performance scores of extension activities as a function of implementation of providing a vision for the future, industry, and the length of service years.

exploratory purposes. Some extension activities may be more effective when officers have worked for a long time. For each type of activity, we conducted a regression analysis of performance score on dummy-coded activity $(0=$ not conducted, $1=$ conducted $)$, service years (median split; $0=$ two years or shorter, $1=$ longer than two years), dummy-coded industry $(0=$ agriculture, $1=$ fishery $)$ and their interactions. It was revealed that service years did not qualify the effects of activities $(|b| \mathrm{s}<.03, p \mathrm{~s}>.051)$, except for "providing a future vision." Three-way interaction of "providing a future vision" $\times$ service years $\times$ industry was significant, $b=14, p=.027$, indicating that, in fishery, the effect of "providing a future vision" was dependent on service years, while it was not in agriculture. As can be seen in Fig. 2, in fisheries, "providing a future vision" had more positive effect on the performance score when service years was longer than two years.

\section{DISCUSSION}

We conducted a nation-wide survey of fisheries extension officers who work for fishing communities in Japan. By combining data with that of agricultural extension officers (Takemura et al., 2014), we examined if the findings on social capital in agricultural communities were replicated in fishing communities.

A series of analyses revealed that, as found in agricultural communities, social capital mattered in fishing communities as well, and extension officers played roles to build and sustain it. First, perceived life quality of community residents were positively associated 
with perceived trust relationships among them, and this association did not differ between agricultural and fishing communities. This suggests the importance of social capital across two different types of communities ${ }^{3}$. Second, the associations between perceived trust relationships among community residents and attributes of extension officers working for the community were also replicated. Not only in agricultural communities, but also in fishing communities, trust relationships among residents was higher when the officer had greater tendency to engage in collaboration and communications with related parties such as agricultural/fisheries cooperatives and local government. Similarly, trust relationships in community was higher when the officer was higher in extraversion, communication skills, as well as agricultural/fisheries knowledge and technical skills. Also, community residents tended to trust each other when the officer had stronger ties with community, and when the officer's colleagues at his or her own workplace (i.e., extension centers) had positive relationships with each other. The latter association suggests a "chain effect" of social capital, meaning positive relationships in one place (extension officers' workplace) also facilitate positive relationships in another place (an agricultural/fishing community) presumably through extension officers' activities. Taken together, these results suggest that agricultural/fisheries extension officers, in fact, influence social capital in agricultural/ fishing communities.

Third, social capital-related extension activities (e.g., assistance for building organizations and collaboration among farmers/fishers), which were effective in solving farmers' problems (Takemura et al., 2014), turned out to be similarly effective in solving fishers' problems. These effects were found not only for aquafarming fishing communities, but also for non-aquafarming fishing communities. Thus, the findings of agricultural communities were largely replicated in fishing communities.

One exception was the effect of providing a vision for the future. Providing a future vision had a positive effect for problem solving in agricultural communities. In fishing communities, this type of activity was more effective when the officer had worked for the community for a long period of time (longer than two years). This conditional effect in fisheries may be explained by the high level of uncertainty due to environmental variability in fisheries (e.g., Roughgarden \& Smith, 1996). If an environment fluctuates, it is difficult to make a precise prediction. Given such characteristics of fisheries, it may matter more who presents the vision for the future. If it is an officer whom fishers have known well and can trust, they may be more likely to believe in the vision and be motivated more to work for it. Presumably, fishers judge the officers' ability to predict the future - which cannot be easily assessed due to the uncertain nature of the future - based on the quality of the relationships that they have with the officers. These relationships require time to be adequately established and assessed, as they are built up by sharing experiences and knowledge with each other ${ }^{4}$.

\footnotetext{
${ }^{3}$ Though the current finding is correlational and therefore silent about causality, Takemura et al. (2014) also reported a time-series analysis which suggests that trust relationships increase life quality of the community residents.

${ }^{4}$ Consistent with this interpretation, supplementary analyses revealed that extension activities to provide a future vision were more likely to be conducted when service years exceeded two years $\left(\chi^{2}=33.58, p<.001\right)$. This may suggest that officers need to wait before conducting this kind of activity until they come to be trusted by farmers/fishers through having a relationship with them for a certain period of time.
} 
This might be the reason why providing a future vision works better among fisheries extension officers when they had worked for the community for a long time.

In summary, the current study revealed that, not only in agricultural but also in fishing communities, social capital matters, and social capital is associated with extension officers' attributes (skills and social relationships). In addition to such commonalities between agriculture and fishery, we also found a difference between them. Effect of a future vision is conditional in fishery while it is not in agriculture, which may be explained by the high level of uncertainty in fishery.

An obvious limitation of the current study is its correlational nature. Future studies need to examine causal relationships by analyzing longitudinal data, for example. It is also important to emphasize that the data was collected through self-report by extension officers. This means that the current paper relies only on the service providers' point of view, rather than the service recipients (i.e., farmers/fishers). However, it is also important to note that relying only on the farmers/fishers' point of view may not be sufficient either to investigate roles of extension activities. Some agricultural extension officers we interviewed emphasized that, to motivate farmers, it is sometimes important to hide the roles of their activities from farmers. Thus, the farmers/fishers may not be aware about the functions of extension activities. It is therefore important to investigate associations between extension activities and communities' welfare from both sides.

Another issue to be examined by future studies is the possibility that the existing level of social capital in a community moderates the effects of extension activities. For example, it seems likely that the agricultural/fishery skills and knowledge that extension officers bring are spread among community members easily when the members trust each other and readily collaborate. If that is the case, extension officers' specialist functions (e.g., teaching new knowledge) and coordinator functions (e.g., promoting the social capital of the community) may have synergetic effects on community welfare.

Also, investigations in other societies such as North America are of importance because Japan is famous for its culture of interdependence or collectivism (e.g., Markus \& Kitayama, 1991). Similarly, it is another open question if the findings of the current research are generalizable for more urbanized communities. The two types of communities we investigated both engaged in primary economic (agriculture and fishery), while tertiary sector is more prevalent in urbanized areas. As Yamawaki (2012) has shown that collectivism is weaker in areas where the percentage of the tertiary economic sector is higher, future studies need to investigate if social coordinators play similar roles in urban communities as in agricultural/fishing communities. Though social relationships are ubiquitous, the underlying processes may be affected by macro-level ecological and societal conditions. Further investigations in different fields are essential to deepen our understanding of human life and psychology.

\section{REFERENCES}

Berry, J. W. 1967. Independence and conformity in subsistence-level societies. Journal of Personality and Social Psychology, 7, 415-418. 
Goldberg, L. R. 1992. The development of markers for the Big-Five factor structure. Psychological Assessment, 4, 26-46.

Gutiérrez, N. L., Hilborn, R., \& Defeo, O. 2011. Leadership, social capital and incentives promote successful fisheries. Nature, 470, 386-389.

Harada, H., Konishi, M., Teraoka, S., \& Ura, M. 2011. Professional skills in the process of establishing human relations within a support framework: Focusing on building community systems supported by public health nurses. Japanese Journal of Experimental Social Psychology, 50, 168-181. (In Japanese with English abstract)

Hidaka, T., Mizuki, S., \& Sato, T. 2014. Facilitator's group maintenance function in Science Cafe: Perspectives on the factors supporting bi-directional communication between the public and scientists. Japanese Journal of Experimental Social Psychology, 54, 11-24. (In Japanese with English abstract)

House, J. S., Landis, K. R., \& Umberson, D. 1988. Social relationships and health. Science, 241, 540-545.

Japan Fisheries Development and Extension Personnel Association. 2009. Fukyu katsudo no tebiki (2009) [Manual of extension activities (2009)]. Retrieved September 17, 2014, from http://www.zengyoren. or.jp/ninaite/pdf/hukyu2009.pdf (In Japanese, the title translated by the current authors)

Markus, H. R., \& Kitayama, S. 1991. Culture and the self: Implications for cognition, emotion, and motivation. Psychological Review, 98, 224-253.

Ministry of Agriculture, Forestry and Fisheries, Japan. 2010. Guideline for management of agricultural extension services: Ministerial Notification No. 590 of MAFF. Retrieved August 18, 2012, from http:// www.maff.go.jp/kinki/seisan/keieishien/fukyu/pdf/h22 shishin.pdf (In Japanese)

Ministry of Agriculture, Forestry and Fisheries, Japan. 2012. Guideline for management of agricultural extension services: Ministerial Notification No. 848 of MAFF. Retrieved August 18, 2012, from http:// www.maff.go.jp/j/seisan/gizyutu/hukyu/h_tuti/pdf/h24_shishin.pdf (In Japanese)

Ministry of Agriculture, Forestry and Fisheries, Japan. n.d. What is extension service? Retrieved August 18, 2012, from http://www.maff.go.jp/j/seisan/gizyutu/hukyu/h_about/index.html (In Japanese)

Morimoto, H. 2009. Step up shuraku eino: Houjin-ka to mura no wa wo ryoritsu saseru [Step up communitybased group farming: Making the incorporation and harmonious relationships in a village go together]. Tokyo: Rural Culture Association Japan. (In Japanese, the title translated by the current authors)

Morita, K., Yagi, H., \& Abe, S. 2009. Capability of large scale rice farms by community-based group farming in the mountainous area: Normative analysis considering farmland conditions in Yasaka Area, Hamada City, Shimane Prefecture. Journal of Rural Planning Association, 28, 141-149. (In Japanese with English abstract)

Mulder, L. B., Van Dijk, E., De Cremer, D., \& Wilke, H. A. M. 2006. Undermining trust and cooperation: The paradox of sanctioning systems in social dilemmas. Journal of Experimental Social Psychology, 42, 147-162.

Pretty, J. 2003. Social capital and the collective management of resources. Science, 302, 1912-1914.

Putnam, R. D. 2000. Bowling alone: The collapse and revival of American community. New York: Simon \& Schuster.

Roughgarden, J., \& Smith, F. 1996. Why fisheries collapse and what to do about it. Proceedings of the National Academy of Sciences of the United States of America, 93, 5078-5083.

Sampson, R. J., Raudenbush, S. W., \& Earls, F. 1997. Neighborhoods and violent crime: A multilevel study of collective efficacy. Science, 277, 918-924.

Svendsen, G. L. H., \& Svendsen, G. T. 2004. The creation and destruction of social capital. Cheltenham, England: Edward Elgar.

Takemura, K., Uchida, Y., \& Yoshikawa, S. 2014. Roles of extension officers to promote social capital in Japanese agricultural communities. PLoS ONE, 9, e91975.

Tsutsui, T. 2005. Chiiki hoken sa-bisu no tantou shokuin ni okeru renkei hyouka shihyou kaihatsu ni kansuru toukei teki kenkyu [Statistical research to develop collaboration index of community health services officials]. Tokyo: Ministry of Health, Labour and Welfare. (In Japanese, the title translated by the current authors)

Uchino, B. N., Cacioppo, J. T., \& Kiecolt-Glaser, J. K. 1996. The relationship between social support and physiological processes: A review with emphasis on underlying mechanisms and implications for health. Psychological Bulletin, 119, 488-531.

Wilkinson, R. G. 1999. Health, hierarchy, and social anxiety. Annals of the New York Academy of Sciences, 
896, 48-63.

Wilson, D. S., O’Brien, D. T., \& Sesma, A. 2009. Human prosociality from an evolutionary perspective: Variation and correlations at a city-wide scale. Evolution and Human Behavior, 30, 190-200.

Wood, B. A., Blair, H. T., Gray, D. I., Kemp, P. D., Kenyon, P. R., Morris, S. T., et al. 2014. Agricultural science in the wild: A social network analysis of farmer knowledge exchange. PLoS ONE, 9, e105203.

Yamawaki, N. 2012. Within-culture variations of collectivism in Japan. Journal of Cross-Cultural Psychology, 43, 1191-1204.

Zakaria, S., \& Nagata, H. 2010. Knowledge creation and flow in agriculture: The experience and role of the Japanese extension advisors. Library Management, 31, 27-35.

(Manuscript received 30 September, 2014; Revision accepted 28 October, 2014) 